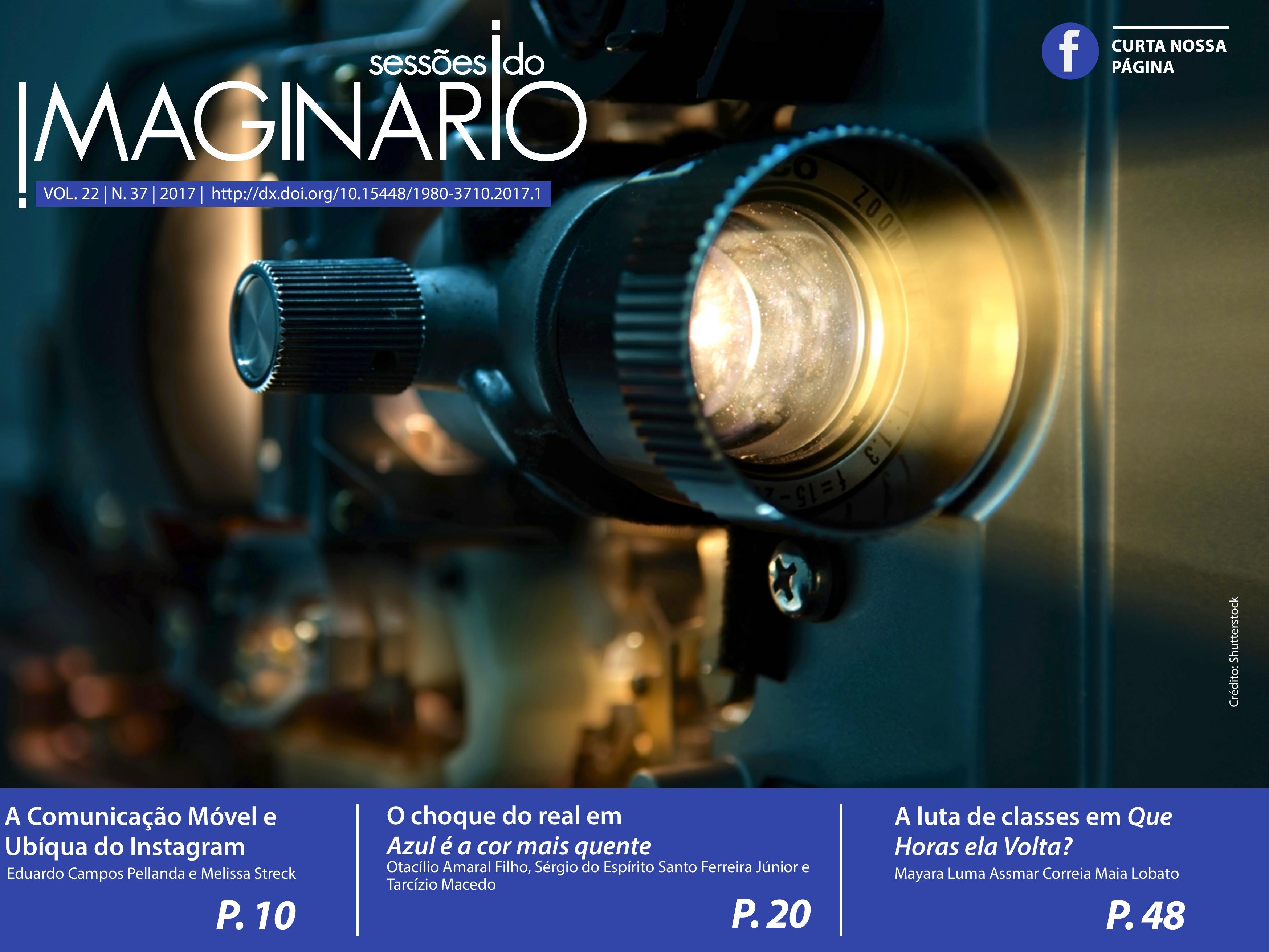




\section{Django Livre e o Western: uma aproximação com a teoria de André Bazin}

\section{Django Unchained and Western:} an approach to the theory of André Bazin

\section{Belisa Figueiró ${ }^{\top}$}

41 PORTO ALEGRE | v. 22 | n. 37| 2017 | pp. 41-47 DOI: http://dx.doi.org /10.15448/1980-3710.2017.1.22614 Sessões do Imaginário

\section{Resumo}

Este trabalho apresenta a teoria do autor francês André Bazin sobre o western e suas diversas ramificações e alterações ao longo das últimas décadas, com especial aplicação na análise do filme Django Livre (Django Unchained, 2012), do diretor norte-americano Quentin Tarantino. Após tantas transformações e readaptações dos filmes ao gênero, será que Bazin legitimaria esta obra cinematográfica dentro dos cânones de pureza propostos por ele?

\section{Palavras-chave}

Western; Django Livre; Quentin Tarantino; André Bazin; gêneros cinematográficos.

\section{Abstract}

This paper presents the theory of the French author André Bazin on Western as a film genre and its various ramifications and changes over the past decades, with particular application to the analysis of the film Django Unchained (2012), directed by Quentin Tarantino. After many changes and usages of the genre films, would the Bazin classification accept this film within its canons of purity?

\section{Keywords}

Western; Django Unchained; Quentin Tarantino; André Bazin; film genre. 


\section{Introdução}

As discussões sobre a origem e a evolução dos gêneros cinematográficos atravessaram as décadas que se seguiram logo após a criação da própria maneira de se fazer filmes e seus autores foram testemunhas do surgimento de novas categorias ou classificações, inspiradas principalmente na literatura. Ao longo do século 21, essas transformações continuam apresentando novos processos para desenvolver gêneros mais atrativos, muitas vezes mesclando modelos já testados, mas nunca de maneira estática.

O western, que segundo André Bazin (1991) é "o único gênero cujas origens quase se confundem com as do cinema", também sofreu modificações ao longo da história e embora tenha deixado de ser um dos principais gêneros da cartela de filmes que se produz na grande indústria norte-americana, continua sendo revisitado de tempos em tempos. Um dos melhores exemplos recentes é Django Livre (Django Unchained, 2012), que foi escrito e dirigido por Quentin Tarantino, um dos diretores mais autorais e criativos dos Estados Unidos - com larga audiência em vários continentes - e assumidamente um apaixonado pelo gênero western.

Mas será que Bazin conseguiria aceitar Django Livre como um western, depois de tantas alterações pelas quais o gênero sofreu, embora retrate temas pertinentes à época e esteja inserido dentro de alguns padrões de pureza considerados pelo autor francês?

\section{Cinema por excelência}

Ainda que elencasse critérios que justificaram o western como o "cinema por excelência", Bazin tam- bém sabia que as suas transformações eram inevitáveis. Entre os anos de 1953 e 1955, ele escreveu seus artigos mais canônicos sobre o gênero, que até hoje são referências teóricas que norteiam não somente as pesquisas acadêmicas, mas também o debate entre os próprios realizadores de filmes.

Naquele começo da segunda metade do século 20, Bazin já conseguia fazer uma análise e um retrospecto dos filmes de western que foram realizados antes e depois da Segunda Guerra Mundial, e o conflito, para ele, foi um marco determinante, principalmente temático. E o mais surpreendente era que os westerns ainda se faziam presentes mesmo depois de tantos anos:

Sem dúvida, o western não escapou completamente à evolução do gosto cinematográfico, sequer do simples gosto. Ele sofreu e sofrerá ainda influências alheias (as do romance noir, por exemplo, da literatura policial ou das preocupações sociais da época), a ingenuidade e o rigor do gênero foram perturbados por isso. [...] Ao invés de lastimar as contaminações passageiras do western, seria melhor maravilhar-se com o fato de ele ainda resistir (Bazin, 1991, p. 199).

E se os filmes de western ainda existiam e encantavam as plateias norte-americanas em função da "perenidade histórica do gênero", era a universalidade geográfica que mais surpreendia Bazin. Isto é, embora os filmes fossem produzidos pelos estúdios de Hollywood e contassem uma história que reconstituísse o nascimento dos Estados Unidos, mesmo assim os mais diversos públicos encontravam elementos de identificação em populações árabes, hindus, latinas, germânicas ou anglo-saxônicas. "É preciso, portanto, que o western encerre algum segredo melhor que o da mocidade: 0 da eternidade; um segredo que se identifica, de alguma maneira, com a própria essência do cinema" (Bazin, 1991, p. 200).

Além de ser movimento por essência, Bazin sabia que era necessário buscar mais elementos que justificassem essa aceitação tão imediata do público, capaz de aproximar diferentes culturas e fazer com que o cinema se transformasse em um produto ao mesmo tempo industrial - cujos estúdios tinham desenvolvido uma determinada fórmula para realizar os filmes - mas também cultural, que exportasse a construção de uma sociedade de tal forma que as plateias de outros países conseguissem enxergar determinadas semelhanças com a sua própria história, ou até mesmo o desejo de acompanhar mais de perto - através do cinema - a evolução norte-americana.

A fidelidade histórica, no entanto, não era uma preocupação da grande maioria dos filmes de western, de acordo com Bazin: "As relações da realidade histórica com o western não são imediatas e diretas, mas dialéticas" (Bazin, 1991, p. 202). Sendo assim, apesar de buscar componentes no passado norte -americano, ainda era preciso considerar novos atributos responsáveis pelo sucesso dos westerns. Um deles seria a sua própria origem na epopeia:

O western é épico, pensa-se geralmente, pela escala sobre -humana de seus heróis, pela extensão de suas proezas. [...] Ao caráter do herói corresponde um estilo de mise-en-scène, em que a transposição épica aparece desde a composição da imagem, sua predileção pelos vastos horizontes, os grandes planos de conjunto, que sempre lembram o confronto do Homem e da Natureza. O western ignora praticamente o 


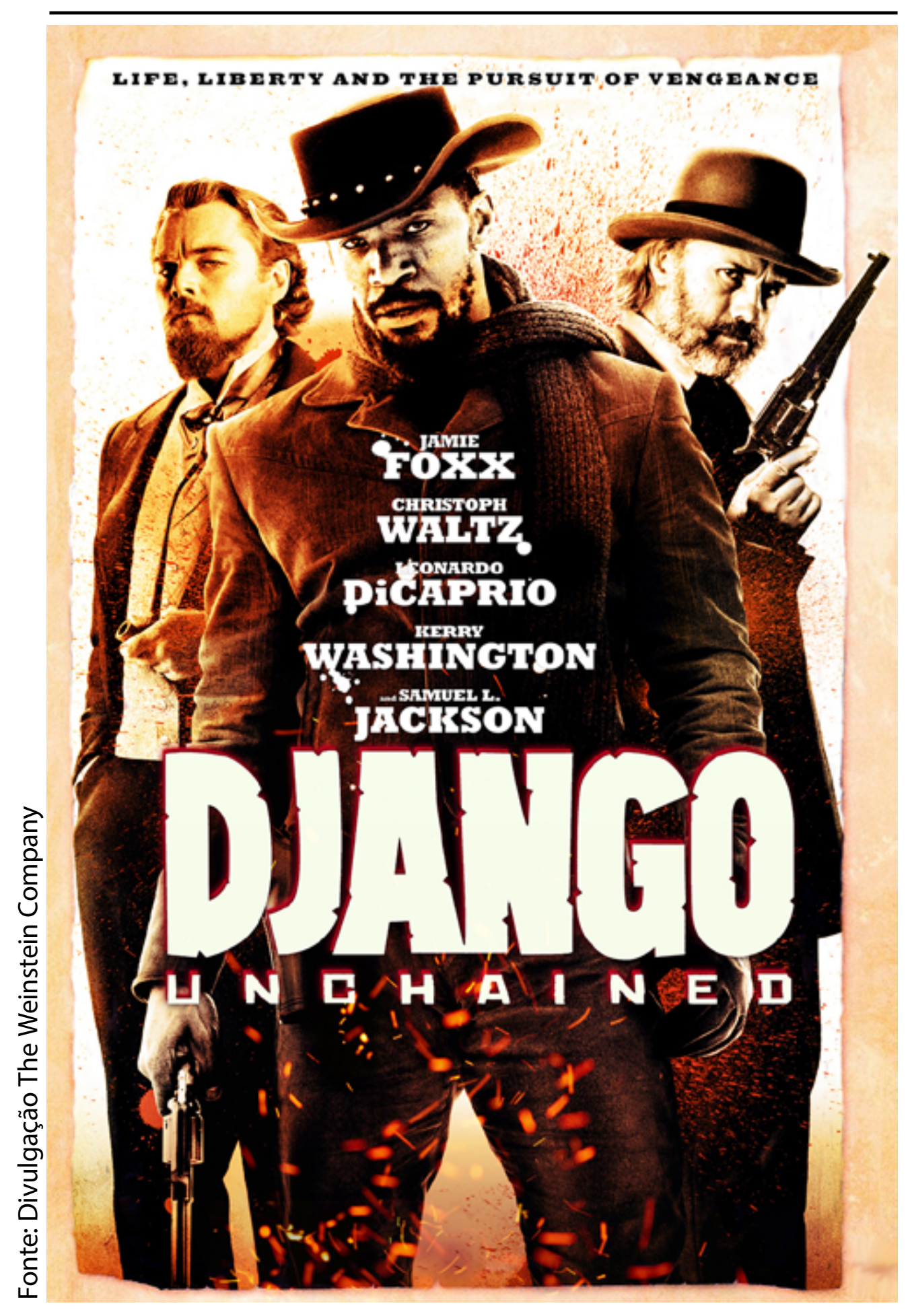

Também é no mito da "Saga do Oeste" que Bazin vai propor uma aproximação com os atributos formais do western. Antes mesmo da realização dos filmes, a literatura e o folclore já buscavam os signos e símbolos dessa composição histórica, construindo personagens, heroicos ou não, baseados em alguns elementos locais que mais tarde seriam retratados pela indústria do cinema.

Para englobar componentes que pudessem justificar a existência de um gênero tanto pela forma quanto pelo seu significado, o teórico Rick Altman (2012) propôs uma aproximação semântico-sintática e que vai justamente ao encontro dessa formulação que Bazin estava buscando sobre os westerns. Bazin já dizia que o western "deve ser outra coisa que não a forma" (Bazin, 1991, p. 201). Em outras palavras, que não bastava reunir um cenário sempre igual, personagens e tramas que começassem e acabassem da mesma maneira.

No entendimento de Altman, isso se traduz em características, atitudes, personagens, planos, locações, decoração e etc. que poderão apontar para um determinado gênero, mas que não haverá uma linha pré-determinada que separe a perspectiva semântica da sintática. "O enfoque semântico, portanto, se concentra nos blocos construtivos do gênero, enquanto que a perspectiva sintática privilegia as estruturas nas quais se dispõem" (Altman, 2012, p. 296). Não há, para ele, portanto, outra maneira de

43 PORTO ALEGRE | v. 22 | n. 37 | 2017| pp. 41-47 Sessões do Imaginário 
se pensar um gênero sem que essas duas linhas de análise sejam combinadas, que trabalhem em complementariedade e muito próximas.

\section{Django Livre mergulhado no western}

A partir de uma análise bazaniana para Django Livre - e também relacionando a essa aproximação entre sentido e forma - é quase inevitável inserir o filme no gênero do western em sua essência.

Bazin faz uma relação direta entre a Guerra de Secessão - também conhecida como a Guerra Civil dos Estados Unidos - e a Guerra de Tróia e aponta o western como responsável pela reincorporação de toda essa mitologia para uma epopeia moderna: "A marcha para o Oeste é a nossa Odisseia" (Bazin, 1991, p. 207). De fato, a maioria dos filmes do gênero western reinterpretaram a história norte-americana e transpuseram para a tela o que no passado foram os combates para se adentrar em solo desconhecido, embora ocupado pelos índios, carregados de violência, como nas antigas batalhas gregas. E nesta releitura da Guerra Civil apresentada por Tarantino, Django Livre apresenta os mesmos elementos e mitos que conquistaram públicos diversos nas décadas passadas, porém propondo uma atualidade que vai ao encontro dos problemas que ainda não foram resolvidos pelas sociedades modernas, como o racismo.

Ao invés do caubói clássico que adentra o povoado e entra em conflito com o xerife local e ainda se apaixona pela mocinha dona do saloon - seja em um contexto de ocupação das terras mais ocidentais ou em plena construção de uma linha férrea que vai dar acesso ao outro lado do país continental -, em Django Livre Tarantino coloca no centro da trama um herói negro que foi salvo justamente por um imigrante alemão. A história se passa em 1858, no sul escravocrata dos Estados Unidos,

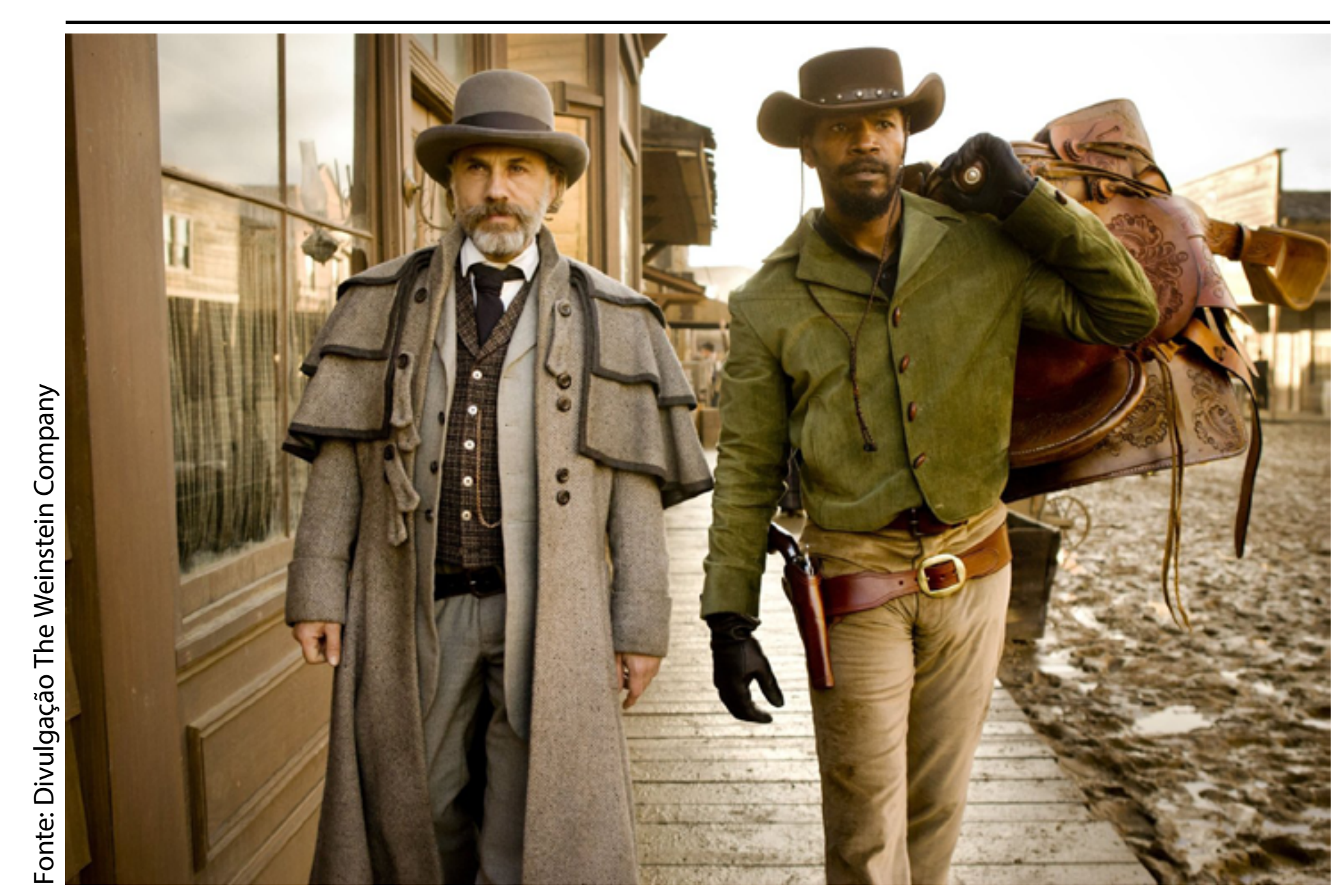

44 PORTO ALEGRE | v. 22 | n. 37 | 2017| pp. 41-47 Sessões do Imaginário 


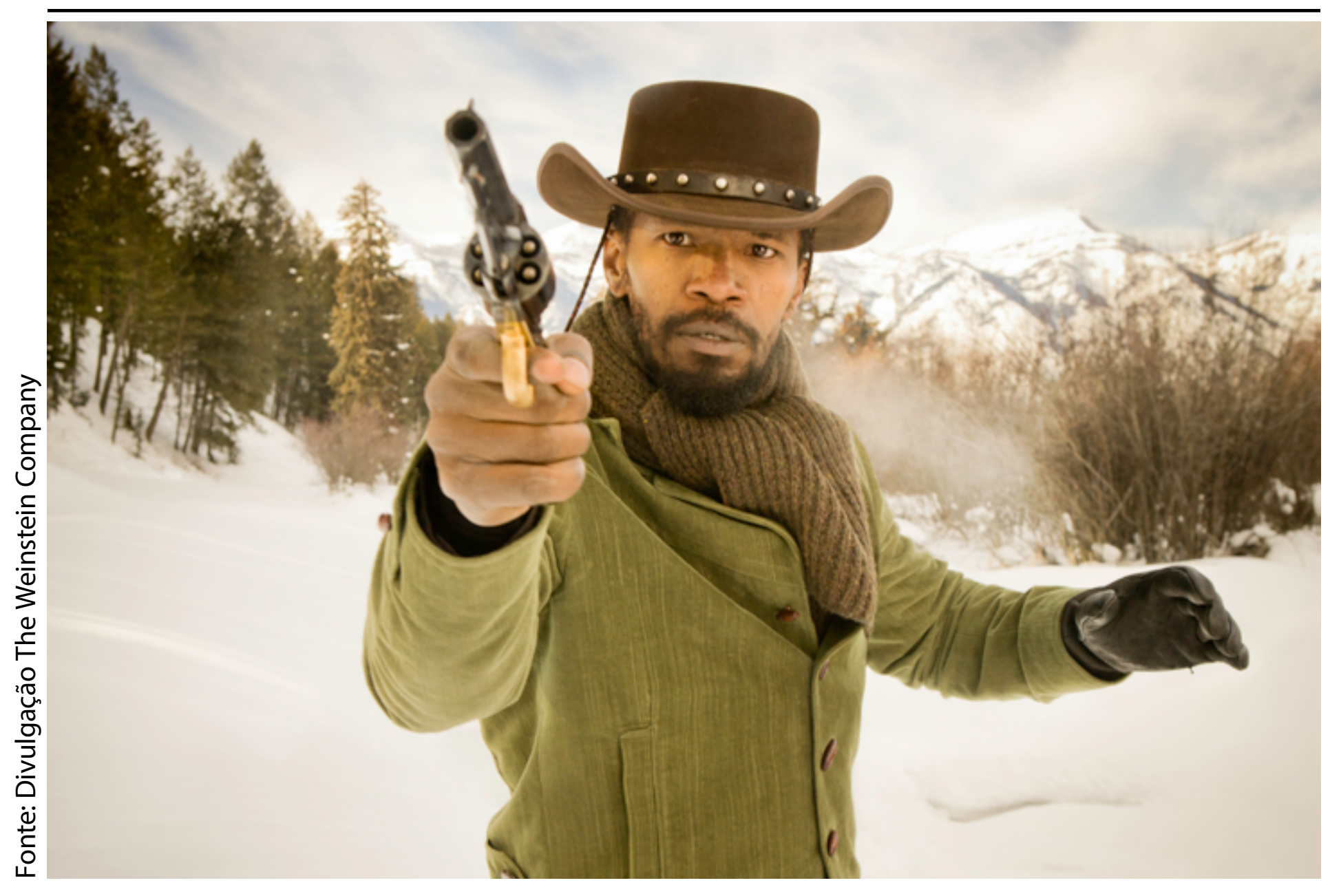

dois anos antes da guerra vencida pelos abolicionistas do norte. Ou seja, o tempo histórico é o da Guerra Civil, indicada por Bazin como o período central dos westerns tradicionais. O saloon é transposto para a casa-grande ${ }^{2}$ das fazendas que exploravam a mão-de-obra escrava, onde vivem os estancieiros que representam o "mau" e na qual acontecem os sucessivos combates ao longo do filme.

A fábula aqui é representada pela jovem e bela Broomhilda (Kerry Washington) que precisa ser salva pelo seu amado, após longas batalhas em terrenos desconhecidos e ambientes hostis. No filme de Tarantino, essa mocinha é uma personagem negra, escrava e que foi vendida separadamente do marido, o herói Django (Jamie Foxx). Logo nas primeiras cenas, somos apresentados a esse personagem que marcha em uma fila de escravos também negros, acorrentados, guiados por seus donos em direção a um lugar desconhecido. O grupo é então surpreendido por um outro viajante, um suposto dentista alemão chamado Dr. King Schultz (Christoph Waltz), que se propõe a comprar o escravo Django ao descobrir que ele conhece três irmãos que estão na lista de procurados pela Justiça. Após o desenvolvimento de um longo diálogo, os donos do escravo se recusam a vendê-lo e acabam sendo baleados e mortos pelo alemão, que liberta Django e os demais condenados.

Este é o primeiro combate do filme, o qual se estabelece aos moldes do western clássico, composto por um diálogo que se prolonga em um tempo fílmico considerável e pelo qual os personagens tentam resolver o problema em questão, mas acabam sempre em um tiroteio seguido de morte. Pelas mãos de Tarantino, esses diálogos carregam também muita ironia, e a violência que se segue não é gratuita, mas explícita e sanguinária. Em determinado momento do longa-metragem, 
um escravo negro fugitivo chega a ser devorado por cães enquanto o bandido e o herói trocam olhares ininterruptos.

Para os públicos mais atuais, a brutalidade do diretor às vezes é vista como exagerada, mas a historiografia comprova que os westerns clássicos nunca foram sutis. Como bem explicita Edward Buscombe, é difícil imaginar um western em que não haja pelo menos uma ameaça de violência.

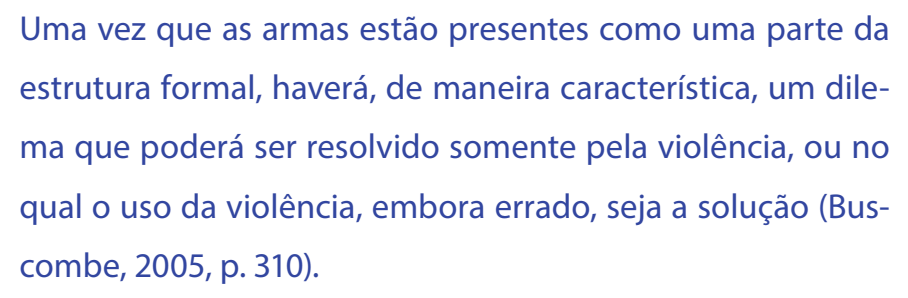

Com a libertação de Django, passamos a acompanhar a trajetória de redenção do personagem, que aceita a parceria com o Dr. Schultz, agora oficialmente apresentado como ex-dentista e atual caçador de recompensas, que mata bandidos procurados pelo Estado em troca de um bom punhado de dólares. Ao se descobrir um excelente atirador, Django se desvencilha dos seus dilemas morais que inicialmente o levavam ao questionamento da atividade e encontra um objetivo maior que justifique a matança daqueles homens brancos foras da lei: acumular uma quantia de dinheiro suficiente que o permita salvar Broomhilda.

Até a metade do filme, acompanhamos a saga da dupla justiceira que percorre o sul dos Estados Unidos ao longo de um inverno rigoroso, sobre camadas profundas e extensas de neve. As buscas dos foragidos são amparadas por documentos legais adquiridos por Dr. Schultz e que servem de álibi para o bom andamento do ofício. Naquela época de formação do país, esse era um fator bem presente e constante nos filmes. Segundo Bazin, "as relações da moral e da lei, que já não passam, para nossas velhas civilizações, de um tema de vestibular, foram, há menos de um século, a proposição vital da jovem América" (Bazin, 1991, p. 204). Em Django Livre, que começa e termina questionando valores sociais em todas as esferas, até mesmo o xerife de um dos povoados é assassinado pela dupla sob a alegação de que é um criminoso perigoso refugiado e escondido em um lugar tranquilo, onde nem mesmo a autoridade máxima da cidade suspeitava de tamanha barbaridade. Uma crítica (in)direta de Tarantino ao sistema policial americano, certamente.

\section{Mulheres de bem}

Além dos personagens típicos de western já citados, Django Livre também trabalha as personagens femininas nos moldes clássicos descritos por Bazin. De acordo com os cânones do autor, o western puro trata as suas mulheres como pessoas dignas de amor, estima ou piedade. Independentemente da sua classe social, sempre serão boas. "A divisão dos bons e maus só existe para os homens" (Bazin, 1991, p. 203).

Neste caso, a nossa heroína Broomhilda não é apenas uma jovem escrava negra. Além de bela, ela também é considerada inteligente e especial por ter sido criada por uma família alemã e falar a língua com fluência quase total. Mesmo tendo tentado fugir com o marido em uma cena que não é mostrada no filme, a bondade da personagem continua intacta. Posteriormente, depois de já ter sido comprada por Calvin Candie (Leonardo DiCaprio) e trabalhar em sua fazenda no Mississippi, Broomhilda foge de novo e acaba sendo resgatada e castigada. No entanto, com a chegada de Django e Dr. Schultz à propriedade, a jovem é libertada da pu- nição para servir o então convidado alemão em todos os sentidos. Ou seja, suas habilidades se sobrepõem ao deslize anterior.

A irmã de Calvin Candie, Lara Lee Candie (Laura Cayouette), também está acima de qualquer perversidade. Apesar de pertencer à família escravista e ser parenta de primeiro grau do maior vilão da história, sua personagem é vista como uma mulher viúva, de boa índole, responsável pela boa condução do serviço doméstico, além de ser bonita, adorável e estar sempre à disposição do irmão. A crueldade que se estabelece no jantar que é seguido pelo trágico desfecho de sua família lhe é totalmente alheia, mas, ao mesmo tempo, intrínseco ao ambiente em que vive. Isto é, ela - e também todas as mulheres escravas que vivem na casa - acaba sendo vítima da maldade masculina que transpira em todos os personagens ali presentes.

\section{Considerações finais}

Em função das transposições feitas por Tarantino, embora diretamente inspiradas em westerns clássicos, talvez Bazin fizesse hoje uma análise cirúrgica e concluísse que Django Livre estaria melhor classificado como um metawestern. Apesar de o tempo histórico ser exatamente aquele considerado como contexto primordial para um verdadeiro western, o filme traz questionamentos que foram adotados mais fortemente pelos westerns realizados depois da Segunda Guerra Mundial. Nas palavras de Bazin:

Digamos que o "metawestern"é um western que teria vergonha de ser apenas ele próprio e procuraria justificar sua existência por um interesse suplementar: de ordem estética, sociológica, moral, psicológica, política, erótica... em suma, por algum valor extrínseco ao gênero que supostamente o enriqueceria (Bazin, 1991, p. 210). 
Ao considerar elementos como o racismo e inclusive relacioná-lo indiretamente às desigualdades sociais do século 21 , além de trabalhar a psicologia de quase todos os personagens e seus dilemas morais, Django Livre poderia se enquadrar nesta subcategoria de Bazin. Entretanto, os componentes cruciais do western estão todos bastante evidentes, desde a apresentação dos créditos iniciais aos finais. Ao invés da epopeia em direção à conquista do Oeste, a guerra que aqui se estabelece é contra a escravidão e todas as suas implicações. As batalhas e o objetivo final não são menos desgastantes e heroicos quanto aqueles do passado real.

Em seu filme anterior, Bastardos Inglórios (Inglourious Basterds, 2009), Tarantino já tinha começado a experimentar o gênero western, focando diretamente na crítica cínica e irônica à Segunda Guerra Mundial e seus diversos lados e desdobramentos. Mas é em Django Livre que ele reúne todos os elementos essenciais para compor o verdadeiro western, até porque o filme também é uma releitura de um outro western: Django, que foi dirigido por Sergio Corbucci, em 1966.

\section{Referências}

ALTMAN, Rick. Film/Genre. London: BFI, 2012.

BAZIN, André. 0 cinema: ensaios. São Paulo: Brasiliense, 1991.

BUSCOMBE, Edward. A ideia de gênero no cinema americano. In: RAMOS, Fernão (org.). Teoria contemporânea do cinema: documentário e narratividade ficcional, v. 2. São Paulo: Senac, 2005, p. 303 - 318.

FREYRE, Gilberto. Casa-Grande e Senzala. São Paulo: Global Editora, 2006.

\section{Referências audiovisuais}

CORBUCCl, Sergio. Django. [Filme-Vídeo] Produção B.R.C. Produzione Film, direção de Sergio Corbucci. Itália, 1966. $92 \mathrm{~min}$. color. son.

TARANTINO, Quentin. Bastardos Inglórios. [Filme-Vídeo] Produção The Weinstein Company, direção de Quentin Tarantino. Estados Unidos, 2009. 153 min. color. son.

Django Livre. [Filme-Vídeo] Produção The Weinstein Company, direção de Quentin Tarantino. Estados Unidos, 2012. 165 min. color. son.

\section{Notas}

1 Mestre em Imagem e Som pela Universidade Federal de São Carlos - UFSCar (Rodovia Washington Luís, s/n, São Carlos - SP, Brasil, CEP 13565-905). E-mail: belisafigueiro@gmail.com.

2 Comparação que faço aqui com a residência oficial das estâncias brasileiras do período colonial escravocrata, em referência ao livro Casa-Grande e Senzala, de Gilberto Freyre (2006). 